\title{
ANÁLISES DE REVISTAS
}

\author{
FISIOPATOI,OGIA
}

Estudos Sôbre ENERVAÇÃo: A - MEtodos. B - A circulaçño FM dedos ENERVADOS. C - INFLAMAÇ̃̃o E ÚlCERAS TRÓFICAS EM ÁREAS ENERVÁdas. D - O mecanismo da vasodilatação axônica. E. - Observações conCERnentes à adrenalina. F - A Circulaçño da pele das partes proximais dos membros. $G$ - Secreção sebácea. H - $O$ efeito do estf́múto ELÉtrico NA CIRCULAÇÃo E No RESTABELECIMENTO do MÚSCULO ENERVADO. (S'TUDIES IN DENERVATION: A - Metiods. B - The circulation IN DENERVATED DIGITS. C - INFLAMMATTON AND TROPHIC ULCERS IN DENERvated areas. D - THE Mechanism OF axonal vasodilatation. F OBSERVATIONS CONCERNING ADRENALINE. F - THE CIRCULATION IN THE SKIN OF THE PROXIMAL PARTS OF THE LIMBS. G - SERACrous SECRETION. H - THE EFFECT OF ELECTRICAL STIMULATION ON THE CIRCULATION AND RECOVERY OF DENERVATED MUSCLES. I - THF CONTRACTILITY OF DENERVATED muscles). J. Doupe, C. H. Cullen, L. J. Macaulay, M. E. Sharp, R. Barnes E A. S. Kerr. J. Neurol. a. Psychiat. (Londres) 6:94-153 (julhooutubro) 1943.

J. Doupe, com a cooperação de alguns colaboradores, empreendeu um extenso e completo estudo sôbre o comportamento de regiōes corpóreas acidentalmente sujeitas à enervação, ante diversos estimulantes externos, experimentais. Para êsse trabalho, J. Doupe utilizou-se de soldados que, em conseqüência mediata ou imediata de ferimentos de guerra, apresentavam, na maioria dos casos, secção .completa de determinados nervos.

A - Inicialmente, é exposta a técnica adotada para variar as condições térmicas e circulatórias das áreas submetidas à enervação. Apesar de que os processos para se medir essas variações não são rigorosamente precisos, êsses métodos são perfeitamente suficientes, desde que seja adotado um critério comparativo e que demonstre o sentido de tais variações.

B - Partindo da hipótese de Lewis e Pickering, explicativa do fato de se manter quente o membro simpatectomizado, enquanto os dedos totalmente enervados tornam-se frios, Doupe faz uma revisão da literatura concernente ao assunto. A seguir, expõe os resultados de experiências pessoais, documentando-as em gráficos. O A. estuda pacientes com simpatectomias ganglionares e pré-ganglionares, bem como indivíduos que sofrem lesões de nervos periféricos. Observou, então, que as reações vasculares nos dedos eram semelhantes em ambos os casos. Nos dedos completamente enervados, foi verificada, entretanto, uma tendência à hipotermia, atribuída pelo A. a uma hipersensibilidade à ação vasoconstritora local exercida pelo frio e causada pela degeneração das fibras simpáticas. Além disso, a ação do frio torna-se mais evidente nos dedos completamente enervados devido à perda maior de calor, condicionada pela vasoconstrição do resto do membro paralisado; ainda no mesmo sentido, influem a ação da adrenalina e o desuso. Por outro lado, 
o estudo comparativo em dedos correspondentes a regiöes integralmente entrvadas e a gangliectomizadas, demonstrou certa diferença no estado habittıal de sua circulação, o que Doupe atríbui à ação de algumas fibras pós-ganglioriares que teriam escapado à gangliectomia. Observou também o A., em dedos totalmente enervados, uma hiperemia reativa depois de haverem sido submetidos à oclusão da circulação arterial. Parece, segundo conclusões de Doupe, que essa reação deve ser atribuída parcialmente a anastomoses artériovenosas, não sofrendo influência pela refrigeração dêsses dedos. Considerações muito interessantes são tecidas sôbre as relações entre a doença de Raynaud e as alterações vasomotoras de dedos enervados. Enquanto na primeira afecção, a principal alteração é um angiospasmo, rebelde à influência dos metabolitos tissulares, nos dedos enervados observa-se a hiperemia reativa mencionada. Tal fato indicaria que o fluxo sangüíneo em lesões de nervos periféricos é proporcional às exigências e necessidades tissulares; pelo contrário, na síndrome de Raynaud, manifesta-se uma isquemia. Como não parece haver deficiência circulatória em dedos enervados, as eventuais perturbações tróficas observadas podem ser atribuídas ao rebaixado metabolismo tissular conseqüente à hipotermia habitual. Discute finalmente o A. a interrelação, existente entre o $\mathrm{pH}$ e o estado vasomotor: uma queda de temperatura, diminuindo a formação dos metabolitos ácidos, conduz, indiretamente, à elevação do $\mathrm{pH}$, o que determina um estado de vasoconstrição.

C - J. Doupe e C. H. Cullen estudam, neste capítulo, as reações vasculares inflamatórias em dedos enervados. Com tal fim, realizaram experiências em dois pacientes: o primeiro, com lesão do nervo cubital direito, sofrera uma queimadura na falange distal do $5 .^{\circ}$ dedo da mão direita; o segundo paciente, apresentando lesão do nervo ciático com discreto edema dos pés, evidenciava pequena úlcera no grande artelho. Concluíram da observação e experimentação nesses pacientes que existiam as reações inflamatórias dos vasos. Este achado confirma a tese anterior de que a irrigação de dedos enervados é suficiente para as necessidades dos tecidos. Dêsse modo, condenam como impróprio o adjetivo "trófico" aplicado a tais úlceras, por isso que èsse têrmo sugere a existência de qualquer defeito na nutrição sangüínea do território correspondente. Por outro lado, a úlcera dos pés é atribuída mais ao edema que pròpriamente à supressão da inervação. A respeito da erupção de vesículas no território de nervos periféricos, sugerem a possibilidade da ação de uma causa extraneurogênica, pelo menos como fator primário.

D - Lewis defendeu recentemente o ponto de vista segundo o qual as fibras relacionadas com a vasodilatação axônica, embora pertençam ao sistema radicular posterior, não são pròpriamente fibras aferentes. Uma observação pessoal de Doupe aparentemente confirma a tese de Lewis. Todavia, uma revisão da literatura parece infirmar a existência, na raiz posterior, de fibras eferentes, quer em animais, quer no homem. Por outro lado, não foi conıprovada a influência das raízes posteriores sôbre a circulação, através de terminações colinérgicas. $\mathrm{O}$ conceito defendido por Gaskell sôbre o contrôle do metabolismo das células cutâneas através das fibras radiculares posteriores, não encontrou qualquer apôio nas pesquisas mais modernas. Finalmente, trabalhos recentes tendem a provar que, com o estímulo dos nervos, certas substâncias vasodilatadoras são libértadas; duvida-se, entretanto, que se trate da substância H. Acredita então J. Doupe que a vasodilatação axônica seja clevida não à substância $\mathrm{H}$ libertada por células cutâneas, mas a produtos do metabolismo de fibras nervosas sensitivas, com potente ação vasodilatadora.

E - Neste capítulo, J. Doupe relata os efeitos, sôbre a circulação de dedos enervados ou simpatectomizados, da adrenalina injetada ou natural- 
mente libertada. Como já fôra verificado no capítulo $\mathrm{B}$, a enervação dos dedos tornava-os hipersensíveis à ação da adrenalina injetada; êsse fenômeno foi atribuído à degeneração das fibras simpáticas. Autores outros haviam demonstrado em "anima nobile", a hipersensibilidade à adrenalina, após gangliectomias simpáticas, nos segmentos correspondentes. Doupe, comparando os resultados da injeção de adrenalina sôbre a circulação de dedos enervados totalmente e pré-gangliectomizados, verificou que, enquanto nos primeiros havia um baixo limiar e resposta prolongada à ação da droga, nos segundos apenas se manifestava o baixo limiar. Em vista de tal comportamento, sugere o A. que essa hipersensibilidade dependa, nos dois casos, de diferentes mecahismos: na enervação total haveria uma perda de "acomodação" condicionada pela degeneração das fibras simpáticas; pelo contrário, na simpatẹctomia pré-ganglionar, não ocorrendo a degeneração de tôdas as fibras simpáticas, apenas se abaixaria o limiar, não se comprometendo, contudo, o mecanismo da "acomodação". A seguir, estuda o A. a secreção da adrenalina, verificando e avaliando sua libertação em resposta a estímulos, incluindo fatores psicogènicos: Constatou, então, que a necessidade da conservação de calor é uma das mais variáveis causas da libertação adrenalínica. Experièncras pessoais do A. levaram-no também a concluir que uma vasoconstrição neurogênica não se acompanha necessàriamente de libertação do hormônio. Doupe, afim de verificar a quantidade e a duração da secreção da droga, realizou estudos comparativos entre os efeitos de estímulos mentais e os da injeção intravenosa da própria adrenalina. Reforçando as conclusões do capítulo B, o A. comprovou que a adrenalina circulante é suficiente para iniciar uma persistente vasoconstrição em dedos enervados.

F - Doupe, Cullen e Macaulay confirmam os resultados obtidos pelas experiências de Grant e Holling (1937-1938) referentes à circulação sangüínea na pele das partes proximais dos membros. Estes últimos autores haviam notadc, nesses segmentos, uma acentuada vasodilatação sob a ação de um aquecimento intenso do corpo. Todavia, após a secção do simpático ou do nervo periférico cutâneo local, a vasodilatação pelo aquecimento não ocorria. Concluíram que os vasos sangüíneos da pele da parte proximal dos membros dependem de nervos vasodilatadores de origem simpática. Estudaram ainda Grant e Holling a importância do papel desempenhado pelas glândulas sudoríparas no mecanismo vasodilatador, apesar de que êsse papel não pareça ser preponderante, devido à freqüente falta de sudorese concomitante com a vasodilatação. As experiências fundamentais de Grant e Holling foram repetidas por Doupe e colaboradores, e seus resultados foram confirmados totalmente. Realmente, entre outros fatos, demonstrou Doupe o aparecimento de vasodilatação cutânea pela estimulação dos nervos simpáticos, reforçando as conclusões dos autores mencionados sôbre a independência dos mecanismos vasodilatadores em função das glândulas sudoríparas.

G - Após uma revisão da literatura a respeito, Doupe e Sharp procuram definir uma eventual relação funcional entre o sistema nervoso (periférico e simpático) e a atividade das glândulas sebáceas. Assim, avaliaram a secrecão sebácea em um paciente com simpatectomia e em um segundo con lesão do plexo braquial. Concluíram pela ausência de qualquer controle do sistema nervoso sôbre a função das glấndulas sebáceas, a qual parece depender de um contínuo processo de crescimento das células das próprias glândulas sebáceas, de maneira análoga ao crescimento dos pêlos ou da epiderme.

$\mathrm{H}$ - $\mathrm{O}$ presente capítulo oferece grande interêsse prático, por isso que se refere aos efeitos do estímulo elétrico na circulação e restabelecimento funcional de músculos enervados, ou seja, ao valor da galvanoterapia trófica 
no tratamento de afecções do neurônio motor periférico. De fato, êsse processo terapêutico, apesar de preconizado e utilizado há cêrca de 40 anos e largamente experimentado em feridos da primeira guerra mundial, ainda deixa dúvidas quanto à sua real eficiência. Doupe, Barnes e Kerr estudam a frequência do restabelecimento da fôrça muscular após sutura do nervo radial, em 12 casos, que foram acompanhados em "follow up", durante 2 anos. Adotaram, em 6 de seus doentes, um tratamento elétrico consistindo em 15 a 30 contrações moderadas de cada músculo, 5 a 6 vezes por semana, induzidas por corrente galvânica aplicada longitudinalmente ao músculo. Essa terapêutica foi empregada, no mínimo, durante 5 meses. Além disso, quase todos os pacientes eram submetidos a massagens, 3 a 5 vezes por semana, durante 6 a 8 meses. Conseguiram os A.A. demonstrar que o fator preponderante para o contrôle do tempo de aparecimento da primeira contração ativa após a neurorrafia, era o nível da lesão. Em nenhum dos casos, evidenciou-se qualquer influência pelo tratamento elétrico. Dêste modo concluem que a eletroterapia, em seu método de aplicação costumeiro, não proporciona qualquer efeito benéfico no restabelecimento da energia contrátil dos músculos. E possível, de acôrdo com Fischer (1939), que essa ineficiência da galvanoterapia dependa da pequena intensidade dos estímulos empregados, quando todos os trabalhos experimentais indicam a necessidade do uso de contrações vigorosas, enérgicas. Como é por todos reconhecido, as contrações musculares determinam um aumento local do fluxo sangüíneo; lembraram-se, então, Doupe e colaboradores de medir êsse aumento em função do trabalho muscular desenvolvido por músculos enervados, em conseqüência a estímulos elétricos. Utilizando correntes muito mais fortes que as comi1mente empregadas na prática terapêutica, verificaram um pequeno aumento relativo do fluxo sangüíneo, evidenciando-se assim que o grau do trabalho imposto ao músculo era discreto. Destarte, concluem os A.A., a única utilicade que a eletroterapia confere aos músculos dependentes de nervos suturados, reside na reeducação e na manutenção da mobilidade tissular.

I - Também muito interessante é êste capítulo com que Doupe finaliza sua série de estudos sôbre enervação. Como sabemos, em casos de supressão da inervação de um músculo (lesão do neurônio motor periférico) aparecem alterações da contratibilidade muscular (contração lenta) e da excitabilidade (tempo de excitação prolongado). O A. procura, neste trabalho, esclarecer as causas determinantes destas alterações, utilizando em suas experièncias principalmente os músculos extensor radial do carpo e tibial anterior, em casos em que se apresentavam enervados. Concluem, nessas experièncias, através da medida do potencial de ação, que cada fibra muscular enervada responde mais de uma vez a um único estímulo, ocorrendo o fenômeno das "excitações repetidas". Dos registros đo A., resulta que uma corrente constante determina estímulos repetidos do músculo cuja inervação foi suprimida. Infere-se que o galvanotono deve depender dêsse fenômeno, e tem mais o caráter de tetanização que de contratura. A contração dos músculos enervados ante excitantes elétricos é considerada lenta; entretanto, notou o A. que essa caraterística se verifica apenas em determinadas condições de estímulo e de temperatura do músculo: quando o músculo enervado estava quente, o estímulo suficiente era pequeno e a contração obtida era quase tão rápida quanto a do músculo normal. A causa da contração lenta verificada comumente na prática, reside, de acôrdo com o A., em que o músculo enervado (especialmente quando frio), tende a sofrer repetidas excitações ante uma corrente constante. De fato, como tem sido demonstrado amplamente, a temperatura do músculo enervado é baixa, muito inferior à do sangue circulantẹ. 
A èsse respeito, cita uma observação đe Leriche, que, explicada à luz de suas verificações, assume particular interêsse; trata-se de um indivíduo com paralisia do nervo radial e CL nos respectivos músculos; entretanto, um bloqueio das fibras simpáticas, tornando o membro quente (vasodilatação paralítica), fazia reaparecer a contração rápida ante o estímulo elétrico. Enquanto Leriche atribuiu essa verificação à aboliç̧áo do angiospasmo do nervo, Doupe a considera como devida à relativa hipertermia produzida no músculo. $O$ tempo de excitação prolongado foi atribuído, em vista dos trabalhos experimentais do A., não só ao já mencionado fenômeno das excitações repetidas, mas também à relação entre as fibras musculares e o campo elétrico da corrente empregada. Resultam dessas considerações fisiopatológicas, interessantes aplicações clínicas concernentes ao eletrodiagnóstico das afecções do neurônio motor periférico. Preliminarmente, o $\mathrm{A}$. frisa que as informações fornecidas pelo eletrodiagnóstico têm mais valor quando positivas que quando negativas. Assim, se há contração em resposta ao estímulo, evidencia-se a presença de tecido contrátil; entretanto, a falta de contração, embora possa indicar total degeneração muscular, pode ser devida, também, a um bloqueio da corrente, por edema ou outra qualquer anormalidade dos constituintes extracelulares do tecido. As mesmas restriçōes podem ser aplicadas à contração lenta. Se esta existe, deve-se admitir que pelo menos algumas fibras têm sua inervação interrompida; entretanto, se a contração fôr fulgurante, normal, podemos concluir apenas que o músculo está quente. Do mesmo modo, a falta de resposta ao estímulo elétrico de um tronco nervoso é de significação duvidosa. A idênticas ressalvas estão sujeitas tôdas e quaisquer medidas da excitabilidade elétrica.

$O$ conjunto dèstes estudos em segmentos ou músculos enervados vem trazer importante contribuição aos conhecimentos sôbre a enervação; seu valor, escapando ao campo puramente experimental, traz imediatas aplicaçōes práticas na clínica diária.

\section{Roberto Melaragno Filho}

\section{MOLESTIAS DO SISTEMA NERVOSO}

Sífilis Meníngea e Vascular da Medila (Meningeal and Vascular syphilis of the spinal cord) R. D. Adams e H. H. Merritr. Medicine (Baltimore) 23: 181-214 (maio) 1944.

Os A.A. estudan as síndromes medulares da lues, com exclusão da tabes. Baseados em dados anátomo-patológicos, classificam-nas em: 1. Meningomielite sifilítica - que compreende a meningomielite amiotrófica de Martin, a paraplegia espástica de Erb, a mielite sifilítica amiotrófica de Leri, a esclerose medular sistematizada de Wilson. 2. Sífilis vascular da medula, de Singer - também conhecida por trombose medular sifilítica ou mielite sifilítica transversa aguda. 3. Paquimeningite medular sifilítica - goma medular $\mathrm{e}$ paquimeningite hipertrófica sifilítica de Joffroy e Charcot. 4. Poliomielite sifilítica de Gowers - os grupos anteriores e a tabes podem produzir atrofia muscular, mas é duvidoso que a sífilis possa produzir, como entidade isolada, uma poliomielite crônica semelhante à atrofia muscular progressiva de Aran-Duchenne. Essas sínaromes consistem em arranjos diversos de três principais sintomas (déficit sensitivo, paralisia vesical e crural, atrofia muscular), porém têm o mesmo substrato anátomopatológico.

Os caraterísticos das síndromes medulares dependem da intensidade, localizaçãoo e extensão da lesão das estruturas pervosas. Esses complexos sin- 
tomáticos consistem em: 1. Transecção completa da medula - pela qual se instala inicialmente o choque medular (arreflexia, hipotonia, paralisia retovesical) ao qual se segue, após 2-3 semanas, um estado de automatismo integral, que pode levar a paraplegia em flexão. 2. Transecção incompleta - nesta, embora se instale também um choque medular, verifica-se posteriormente o predomínio dos reflexos antigravitários nos membros inferiores, surgindo paraplegia em extensão. A transecção medular, completa ou incompleta, nunca produz amiotrofias. 3. Lesão parcial da medula, que compreende: síndrome de Brown-Séquard; amiotrofia - lesão das células motoras ou das raízes anteriores - cujo quadro clínico pode-se assemelhar ao da poliomielite aguda ou ao da atrofia muscular progressiva (se a via piramidal fôr lesada, tem-se o quadro da esclerose lateral amiotrófica; pode haver distúrbios sensitivos, desde que sejam atingidos os feixes ascendentes); síndrome tabética, por destruição dos funículos posteriores; lesão combinada de sistemas (se à ataxia sensitiva se superpõe paralisia, por lesão do feixe corticospinhal, tem-se uma paraplegia atáxica); síndrome siringomiélica, explicada por lesão central da medula.

No capítulo da patologia, estabelecem os AA. que é excepcional uma forma pura de lesão sifilítica medular sem lesão do encéfalo. Usualmente, há comprometimento de várias porções do neuraxe. $O$ processo anátomo-fatológico básico da sífilis medular é uma leptomeningite crônica. Desconhece-se a maneira exata pela qual a medula e as raízes são lesadas pela leptomeningite crônica; os AA. julgam que os espiroquetas provocam leptomeningite e também atuam sôbre os tecidos vizinhos. A lesão vascular encontrada é endarterite luética de Heubner; en grande número de casos, encontram-se tanto processos meningíticos como arteríticos $\mathrm{e}$, por isso, não se pode esclarecer a relação entre as lesões das artérias, a processo meníngeo crônico e a degeneração parenquimatosa. A endarterile luética pode levar ao enfarte medular, com mielomalácia e formação de savidades. A paquimeningite medular é uma inflamação peridural intensa e em focos (goma) ou moderada e difusa (paquimeningite hiperplástica). A patogenia das gomas é desconhecida; as localizadas nas meninges medulares são histopatològicamente granulomas específicos idênticos aos encontrados em qualquer outro setor do organismo. A goma meníngea pode comprimir ou invadir a medula, destruindo células e fibras nervosas. A sífilis da raque, afetando secundàriamente a medula "is so rare as to hardly deserve discussion". A combinação dos processos meningítico, arterítico e gomoso pode simular qualquer moléstia medular. Nenhuma dessas reações patológicas é absolutamente patognomônica da sífilis, mas, tomadas em conjunto, elas são altamente caraterísticas.

Tratando da freqüência, os AA. afirmam que a sífilis medular é uma raridade clínica. Quanto aos períodos médios de latência, êles variam de 24 anos para a meningomielite, 10 anos para a paquimeningite e 6 anos para a sifilis vascular. Passam, depois, a considerar a sintomatologia. $\mathrm{Na}$ meningomielite luética, a instalação é insidiosa, com fraqueza ou rigidez e parestesia nos membros inferiores; no período de estado há uma paraparesia ou paraplegia espástica e distúrbios da micção e defecação. As perturbações sensitivas são mais tardias e variam muito; só em um têrço dos casos pode-se precisar um nível sensitivo definido; pode haver dôres na região dorsal ou circuntorácicas, porém nunca têm caráter fulgurante. Em certos casos há sintomas mentais ou paralisias de nervos cranianos; a trombose das artérias medulares converte a paraparesia espástica em paraplegia flácida com retenção urinária e anestesia. A evolução é geralmente progressiva, às vezes com ep:sódios agudos; a parada espontânea existe, mas jamais ocorre a remissão 
completa. A tríade sintomática caraterística da sífilis vascular da medula consiste em: início súbito de paralisia flácida do tronco e membros inferiores, anestesia dessas regiōes e perda do controle esfincteral. Esses fatos correm por conta, geralmente, de obstrução da artéria espinhal anterior, responsável pela irrigação dos dois terços anteriores da medula. Sòmente um têrço dos casos tornam-se espásticos; alguns dos restantes apresentam paraplegia em flexão. Este quadro pode aparecer por outras causas (abscesso epidural agudo, metástase epidural carcinomatosa, polisclerose e mielite infecciosa aguda); o tratamento visa apenas prevenir tromboses subseqüentes. Os AA. têm conhecimento de 16 casos, tendo a trombose ocorrido espontâneamente em 10 e, após tratamento, em 6 . Não acreditam na existênc.a de uma reação de Herxheimer no decurso do tratamento da neurolues, mas advertem contra os perigos da introdução intra-raquídia, em neurossifilíticos, de qualquer substância estranha. A amiotrofia é rara nos neuroluéticos, mas pode existir na atrofia muscular progressiva de origem luética e associada à tabes (em $5-10 \%$ dos casos), à meningomielite sifilítica (a amiotrofia é explicada pela lesão das raízes anteriores, ao passarem pelo envoltório meníngeo inflamado), à sífilis vascular da medula. Na casuística dos AA. há três observações de gomas que evolveram como tumor de crescimento rápido; o líquor apresentava a síndrome e Froin e a reação de Wassermann era positiva. O início fôra insidioso; os sintomas constaram de dôres radiculares e parestesia abaixo do nível da goma. Em outro caso, tratava-se de paquimeningite medular hipertrófica sifilítica, cuja sintomatologia era caraterizada por dôres e parestesias nos membros superiores, seguidas depois por paralisia atrófica dêsses membros, anestesia segmentar e paraplegia espástica; o líquor era idêntico ao dos casos de goma. A evolução lenta e a tendência à amiotrofia segmentar parecem distinguir esta entidade clínica, das gomas. Os AA. atribuem às seguintes causas a compressão medular devida à sífilis: goma da leptomeninge, goma vertebral (cuja existência é negada por vários patologistas), aneu. risma da aorta descendente com erosão de vértebra, paquimeningite sifilítica (que determina constrição da medula).

Os AA. ilustram o trabalho com a descrição de 10 casos; em 7 foi realizado c exame anátomo-patológico.

Em grande percentagem, sangue e líquor são anormais, especialmente nos casos ativos; só em um dos casos (em que o diagnóstico de poliomielite sifilítica era discutível) foram ambos negativos; entretanto, os AA. admitem que, tanto o sangue como o líquor poderiam ser negativos, se o número de observações tivesse sido maior; isto dificultaria muito o diagnóstico. A negatividade liquórica não coexiste com a progressão clínica. Os dados que podem servir de base para diferençar as várias entidades de neurolues medular são: período de latência, modo de instalação, evolução, sintomas, sinais e caracteres do líquiido cefalorraquídio. Os resultados do tratamento são, em geral, desencorajadores. A maioria dos pacientes com paralisia completa sucumbe dentro de um ano, no máximo, devido a úlceras tróficas, septicemia, broncopneumonia, tuberculose pulmonar ou pielonefrite. Os AA. julgam que o mafarsen e a neoarsfenamina com bismuto e iodeto de potássio determinam a negatividade liquórica; depois de um tratamento de rotina durante 6-12 meses, se não houver melhora do quadro liquórico, deve-se experimentar a triparsamida. Duvidam que a malarioterapia seja sempre indicada, exceto possìvelmente em casos de melhora clínica mas com anormalidades liquóricas persistentes; neste caso, a malária teria o papel de prevenir que se estabelecessem outras formas de neurolues parenquimatosa. A assistência geral do paciente paralítico consiste na prevenção das escaras, atenção aos distúrbios 
esfincterais, cuidados com os músculos enfraquecidos, movimentação passiva regular; no caso de contraturas em flexão, é indicada a rizotomia anterior de Munro.

\section{H. Canelas}

Reconhecimento e Tratamento das Deficiências Vitamínicas Iniciais (EARly DEFiCIENCY Diseases: their RECOgNition and treatment). J. M. Ruffin, M. Clin. North America 27 :485-499 (março) 1943.

Os doentes denominados, usualmente, de neuróticos, por apresentarem uma queixa vaga e polimorfa (fraqueza, nervosismo, anorexı́a, má digestão, cefaléia, dor nas costas, palpitações) constituem um problema nas clínicas reurc-psiquiátricas. Quando os exames subsidiários não trazem nenhuma informaçãc, o médico tem a tendência de rotulá-los como casos psiquiátricos. Impõe-se, porém, investigar a deficiência vitamín:ca que, quando no início ou frusta, pode produzir tais sintomas. Esses casos são de diagnóstico difícil. porquanto os sinais físicos só surgem num grau mais avançado da deficiência. $O$ exame deve constar da história dietética, do exame clínico, neurológico e psiquiátrico, das pesquisas acessórias (quadro sangüíneo, exame de urina e fezes, prova de Katsch, gastroscopia, proctoscopia e biópsia de nervo), das determinações vitamínicas (difíceis e ainda não padronizadas) e dos testes terapêuticos. O quadro neuro-psiquátrico é constituído por: diminuição ou perda, em bota, da palestesia; hipoalgesia e hipoestesia; reflexos normais (embora, às vezes, os aquileus se encontrem diminuídos ou ausentes); ocasionalnente, hipotonia dos músculos da panturrilha; viscosidade mental. Incluímos o quadro sintomatológico de Mackie modificado pelo $\mathrm{A}$ :

\begin{tabular}{|c|c|c|}
\hline $\begin{array}{l}\text { DEFICIEN- } \\
\text { CIA VITA- } \\
\text { MINICA } \\
\end{array}$ & SINTOMAS E SINAIS & DADOS DE LABORATORIO \\
\hline $\mathbf{A}$ & $\begin{array}{l}\text { Cegueira noturna, alterações na } \\
\text { conjuntiva, pele rugosa. }\end{array}$ & $\begin{array}{l}\text { Diminuição do teor sangüíneo de } \\
\text { vitanina A. }\end{array}$ \\
\hline $\begin{array}{l}\text { TIAMINA } \\
\left(B_{1}\right)\end{array}$ & $\begin{array}{l}\text { Parestesia das extremidades, hipo- } \\
\text { palestesia, hiporreflexia tendino- } \\
\text { sa, hipotonia muscular. }\end{array}$ & $\begin{array}{l}\text { Diminuição da excreção urinária } \\
\text { de tiamina. Degeneração neural } \\
\text { revelada pela biópsia. }\end{array}$ \\
\hline $\begin{array}{l}\text { AC. NICO- } \\
\text { TINICO }\end{array}$ & $\begin{array}{l}\text { Ulceraçōes bucolinguais, vermelhi- } \\
\text { dāo e atrofia papilar, asperezrn } \\
\text { da pele, nas māos e proeminên- } \\
\text { cias ósseas. }\end{array}$ & $\begin{array}{l}\text { Diminuição da excreção urinária } \\
\text { de ácido nicotínico. }\end{array}$ \\
\hline $\begin{array}{l}\text { RIBOFLA- } \\
\text { VINA }\end{array}$ & $\begin{array}{l}\text { Fotofobia e lacrimejamento, qusi. } \\
\text { lose, "lingua magenta". }\end{array}$ & $\begin{array}{l}\text { Vascularização da córnea e dimi- } \\
\text { nuição da excreção urinária de } \\
\text { riboflavina. }\end{array}$ \\
\hline $\mathrm{C}$ & $\begin{array}{l}\text { Gengivas esponjosas, sangrantes e } \\
\text { petéquias. }\end{array}$ & $\begin{array}{l}\text { Diminuição do teor plaşmático de } \\
\text { vitamina. C. }\end{array}$ \\
\hline D & Fraqueza muscular. & $\begin{array}{l}\text { Diminuição do fósforo sangüíneo, } \\
\text { elevação da fosfatase sérica, al } \\
\text { teraçoses radiológicas. }\end{array}$ \\
\hline $\mathbf{K}$ & Hemorragias. & $\begin{array}{l}\text { Aumento do tempo da protrombi- } \\
\text { na. }\end{array}$ \\
\hline
\end{tabular}


O tratamento inclui uma dieta bem balanceada e a administração parenteral de vitaminas durante 3 a 5 dias, seguida pela administração oral. $O A$. recomenda as seguintes doses de vitaminas (via oral) no tratamento das carências discretas :

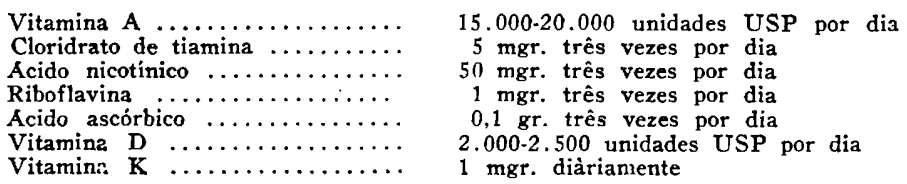

As deficiências vitamínicas respondem bem e ràpidamente ao tratamento. Se não advier melhora clínica após 10 a 14 dias, nas carências. de vitaminas hidrossolúveis, trata-se de um êrro diagnóstico ou significa que tiveram lugar alterações irreversíveis, sendo inútil continuar a terapêutica. Tratando-se de déficit de vitaminas lipossolúveis, pelo contrário, o tratamento precisa ser muito mais prolongado.

\section{J. M. TaQues Bittencourt}

\section{RADIODIAGNÓSTICO}

FAdiodiagnóstico das afEç̧ões da COLUNa vertebral (Radiodiagnóstico de las AfECCiONES DE LA COLUMNA VerTebral) Luís Opazo Radiol. (Buenos-Aires), 6:199-210 (setembro-dezembro) 1943.

Inicialmente, o A. cogita das dificuldades técnicas do exame radiológico da coluna vertebral nos segmentos dorsal alto e lombar inferior, as quais decorrem das superposições, não só das próprias vértebras, como dos ossos das cinturas escapular e pélvica. Lembra a necessidade de serem praticadas radiografias nas incidências de perfil, sagital e oblíquas, estas últimas bastante úteis, pois permitem visualizar os pedículos vertebrais e as articulações apofisárias. Quando essas incidências não bastarem, recomenda o auxílio da estereo-radiografia, da planigrafia e das mielografias com contraste gasoso ou iodado. Acentua, porém, que a mielografia iodada deve ser praticada apenas nos casos em que se seguir a intervenção cirúrgica, por sofrer o lipiodol no canal raquidiano as transformações de saponificação do meio olcoso.

Em radiologia, muitos diagnósticos passam desapercebidos por falta de exame completo, devido ao número insuficiente de radiografias praticadas, e também pelo fato de que muitas afecções da coluna (como, aliás, tôdas ás do esqueleto), só se manifestam radiològicamente quando já existem lesões neurológicas, isto é, quando o processo já está bastante evoluído clinicamente para que sejam produzidas lesões destrutivas ou'proliferações ósseas importantes.

Passa em seguida ao estudo do menisco intervertebral, que em certas enfermidades da coluna é o sítio de fixação de alguns sinais radiológ:cos carater ísticos que permitem o diagnóstico insofismável daquelas afeç̧ões, principalmente as de tipo degenerativo, que podem correr por conta de traumas antigos aparentemente inócuos ou ainda seqüelas de estados infecciosos que tiveram fixação nos meniscos.

Estudando a tuberculose da coluna, recorda que a sua localização inicial É sempre óssea, e que, secundária mas precocemente, se faz a invasão do menisco intervertebral. $\mathrm{Na}$ grande maioria das observações radiológicas de mal de Pott, o processo já se propagou para o menisco que, sendo cartila- 
ginoso e, portanto, pobre em vasos sangüíneos, favorece uma propagação rápida, determinando conseqüentemente um achatamento ou fusão das vértebras. As lesões marginais dos corpos vertebrais (que se situam na parte anterior ou lateral, e mais raramente na posterior) em conseqüencia do achatamento do menisco e da desintegração óssea vertebral, e secundàriamente devido à grande atividade muscular exercida sôbre a coluna, determinam em breve tempo a fusão da vértebra ou das, vértebras afetadas, resultando as deformações caraterísticas do mal de Pott; essas deformações se apresentam em percentagem elevada. O processo tuberculoso se assesta $\mathrm{em} 1$ ou em 2 corpos vertebrais vizinhos, propagandando-se às vértebras próximas através do ligamento vertebral comum anterior. Em casos de evolução maligna, o' processo de propagação engloba 3 ou 4 peças vertebrais quase simultâneamente, trazendo em breve a deformação da coluna e acarretando sintomas de compressão medular, que se produzem mecânicamente pela própria gibosidade ou pelos abscessos ossifluentes que se propagam ao canal raquidiano. Esses abscessos constituem uma complicação freqüente do ma! de Pott. Em sua revisão estatística, o A. encontrou só 3 casos de cvolução atípica de mal de Pott, consistindo na localização bifocal (localização simultânea em um mesmo segmento ou em segmentos vizinhos, deixando entre os focos várias peças vertebrais indenes). Estuda ràpidamente o diagnóst:co diferencial, que é feito com a osteomielite, a lues, a brucelose da coluna e a espondilite tífica. O diagnóstico radiológico nunca deve ser feito baseado ùnicamente no aspecto das radiografias, mas fundar-se na observação do enfêrmo e na análise documentada da sintomatologia.

Entre as afeç̧ões degenerativas da coluna, o A. distingue 2 grupos bem caraterizados: 1 . Os processos degenerativos que se iniciam no tecido ósseo vertebral; 2. os processos degenerativos próprios do menisco intervertebral. Estuda, entre as primeiras, a enfermidade de Kummel-Verneuill, cuja etiologia reside em pequenos traumas destituídos de importância e que acarretam um processo reacional que termina em cifose dolorosa. A descalcificação senil da coluna de tipo osteomalácico que termina quase sempre pela fusão espontânea de um corpo :vertebral, sem trauma direto, senão aquêles resultantes de esforços musculares habituais, está ligada provàvelmente a um distúrbio do metabolismo do cálcio e do fósforo. A impregnação calcárea do núcleo pulposo é outra afecção degenerativa que se expressa nas radiografias de perfil como manchas lenticulares calcificadas que ocupam o centro dos meniscos. Esta afecção constitui um achado radiológico, pois que não acarreta sintomatologia, ou apenas sintomas vagos e imprecisos. A impregnação calcárea dos rodetes marginais das vértebras corsais e lombares, e em menor grán das cervicais, é mais freqüente que as afeç̧ões degenerativas anteriormente estudadas, sendo atribuída a sua crigem a um transtôrno do 'metabolismo geral, possivelmente de origem endócrina ou reumática. Os transtornos degenerativos de origem traumática mais interessantes são constituídos pelas hérnias do núcleo pulposo, em que, por ação de um trauma geralmente no sentido vertical da coluna, se produz o encrustamento do núcleo pulposo na cartilagem de revestimento da superfície articular, produzindo-se a hérnia ou o pinçamento intra-ósseo, e quando o trauma é mais violento produz-se a hérnia verdadeira do núcleo pulposo, ou seja a sua emigração para o canal raquidiano.

O trabalho é acompanhado de vários clichês radiográficos documentativos.

Celso Pereira da Sirva 
RADIODIAGNóstico DO CÂNCER DA COL.UNA VERTFBRAL (RADIO-DIAGNÓSTICO DFL CANCer de la col.umna vertebrai.). Felix Daza Radiol. (Buenos Aires), 6 : 211-219 (setembro-dezembro) 1943.

Sob a denominação geral de câncer da coluna vertebral. o A. considera os tumores malignos (primitivos. metastásicos e de vizinhança), os quais, $\mathrm{em}$ sua forma histopatológica, podem corresponder aos sarcomas, carcinomas ou mielomas. Os transtornos sensitivos e motores são os principais sintomas da enfermidade, apresentando-se entre os primeiros as aloias e alteracões da sensibilidade, e entre os segundos as paresias e paralisias. O câncer da coluna se apresenta sob dois aspectos radiológicos: osteolítico e costeosclerítico. havendo ainda a forma mista, que corresponde ao desenvolvimento simultâneo dos dois tipos. Tece considerações rápidas a respeito do diagnóstico radiológico de cada uma das formas. Considera a forma osteolítica como sinónima de câncer secundário da próstata, pois só a observou como metástases dos tummores dêsse órgão. Com relação às rias de invasão, lembra que os sarcomas osteogênicos ou primitivamente €xtra-ósseos não dão lugar a focos secundár:os na coluna. A via cie invasão é a sangü̉nea, e no caso das metástases secundárias a um câncẹ de próstata existem duas teorias, uma que admite a via linfática e outra a sangüínea. $O$ diagnóstico diferencial do câncer osteolítico é feito com a enfermidade de Albers-Schönber, da qual se distingue porque nesta todo o esqucleto é comprometido, e no câncer a invasão da coluna é progressiva e só nos cassos avançados atinge as costelas $\mathrm{e}$ as extremidades dos membros. $\mathrm{O}$ câncer osteolítico deve ser diferençado da espondilite tuberculosa e das fraturas de vértebra. No mal de Pott há comprometimento precoce do menisco, enquanto que no câncer o menisco é conservado. A fratura se distingue em alouns casos só com o auxílio da anamnese e do exame clínico cuidadoso.

O material estudado pelo A. é constituido por 1.699 doentes que passaram pelo Laboratório Central de Radiologia do $H$. Salvador de Santiago cio Chile durante um periodo de 7 anos. Dêsse total de doentes radiografados, 853 apresentavam colunas patológicas e entre essas havia 42 casos de câncer vertebral. Dêsse estudo o A. depreende: 1. A raridade dos t11mores primitivos da coluna. 2. A freqüência extraordinária das metástases nos tumores primitivos da próstata, útero e mama. 3. A grande percentágem de cânceres de origem não identificada, apesar dos minuciosos exames clínico e paraclínicos efetuados. 4. A raridade das metástases nos casos de câncer primitivo do estômago, o que está de acórdo com as estatísticás de outros autores. 5. Os casos de bócio maligno operado não apresentaram metástases vertebrais.

\section{Celso Pereira da Silva}

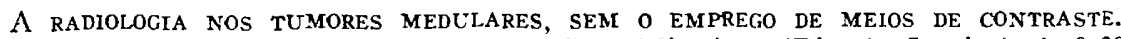
Nicola C. Caminha. An. Santa Casa Miseric. (Rio de Jane.ro) 1:9-28 (maio) 1944.

A negatividade dos espondilogramas para o diagnóstico das afecções neoplásticas da medula e seus envoltórios, fez com que os neuro-radiologistas se socorressem da mielografia, que proporcionou esclarecimentos amplos, 11ão só quanto à situação dos tumores no canal raquidiano, mas também quanto à sua extensão e localização intra ou extradural. Posteriormente, com a aparição dos trabalhos de Camp-Adson e de Elsberg-Dyke, foi verificada a possibilidade do diagnóstico e da localização dos tumores medu- 
lares só com o auxílio da radiografia simples, devido às alterações ósseas vertebrais determinadas pela neoplasia. Aperfeiçoamento das ‘́écnicas radiográficas, estudo mais apurado da anatomia radiológica da coluna e pesquisas mais cuidadosas das pequenas alterações estrúturais ósseas, foram as causas que, na opinião do A., motivaram êste melhor aproveitamento cios espondilogramas.

Após a revisão dos diversos tipos histológicos de tumores intra-raquidianos (intramedulares, intradurais, extramedulares e extradurais), sua freqüencia e sede na coluna vertebral, segundo as estatísticas de Elsberg, o A. faz uma rápida digressão sôbre cada um dos principais tipos de tumor.

Passa, em seguid̦a, ao estudo das alterações ósseas vertebrais ocasionadas pelos tumores intra-raquidianos, as quais se processam em conseqüência do crescimento progressivo do tumor e comprometem a face posterior do corpo vertebral, os pedículos, as lâminas e a base das apófises espinhosas, segundo a direção em que o crescimento do tumor se efetua. Para a verificação das modificações da coluna, são necessárias radiografias perfeitas nas incidências habituais. A alteração do corpo vertebral se faz especialmente na face posterior e consiste em erosão de um ou mais corpos vertebrais. Os meningiomas e os neurinomas afetam, em geral, um só corpo de vértebra, enquanto que os ependimomas atingem vários corpos vertebrais contíguos. A alteração das lâminas, bem mais difícil de ser percebida em conseqüiência das superposiçóes e da delicadeza de seus contornos, só é realizável na coluna lombar. A alteração da apófise articular é rara. A alteração dos pedículos é a mais freqüente e a mais importante; consiste na erosão dc bordo mediano dos pedículos, que se torna irregular ou côncavo, podendo mesmo ser completamente destruído.

Além das alterações ósseas, o autor chama a atenção para um outro recurso de valor, que é a curva raquimétrica de Elsberg-Dyke. Ela é obtida lançando-se em gráfico as distâncias interpediculares (distância entre os bordos medianos dos pedículos vertebrais) de tôda a coluna. Figurando no eixo das abscissas a numeração das vértebras, de $\mathrm{C}_{5}$ a $\mathrm{L}_{5}$ (impraticável nas primeiras cervicais e nas sagradas) e no eixo das ordenadas as distâncias, em milímetros, de 16 a 39 , que são os valores extremos encontrados, obtém-se uma curva irregular e caraterística. O traçado obtido é horizontal na região cervical, descendente progressivamente nas 4 primeiras dorsais (diminuição da distância interpedicular), mantém-se novamente horizontal nas 4 vértebras dorsais seguintes, para se elevar lentamente até as últimas lomhares. A curva raquimétrica é constante em tôdas as idades. Não é influenciada pela distância foco-placa e nem pelas curvaturas da coluna (cifose e lordose). Ela retrata as modificaçóes de diâmetro da medula e seụs envoltórios. O aumento da distância interpedicular determinado pelo tumor $r$ se traduzirá, na curva raquimétrica, pelo aparecimento de um "gancho ou dente", que, para ter valor patológico, necessita de uma amplitude mínima de 3 milímetros. A curva raquimétrica pode localizar o tumor intra-raquidiano, mesmo quando não são encontradas as alterações ósseas do pedículo.

O A. documenta o trabalho com gráficos ilustrativos e clichês radiográficos que muito esclarecem o assunto.

Cello Pereira da Silva 